\title{
Gossypol enhances radiation-induced autophagy in glioblastoma multiforme
}

\author{
Hoda Keshmiri-Neghab ${ }^{1}$, Bahram Goliaei ${ }^{1}$ and Alireza Nikoofar ${ }^{2}$ \\ ${ }^{1}$ Laboratory of Biophysics and Molecular Biology, Institute of Biochemistry and Biophysics (IBB), University of Tehran, Tehran, \\ Iran \\ 2 Department of Radiotherapy, Firoozgar Hospital, Iran University of Medical Sciences, Tehran, Iran
}

\begin{abstract}
Malignant gliomas (glioblastoma multiforme) are the most aggressive of the primary brain tumors. Radiotherapy is an important tool for treatment of cancer but malignant gliomas are usually resistant to radiotherapy and other adjuvant therapies. Thus new drugs are needed to increase the efficiency of radiotherapy in order to improve the therapeutic outcome of tumor patients. Recent investigations showed that gossypol, natural polyphenolic compound produced by cotton plants, is a promising agent against solid tumors. The current study was defined to evaluate whether the combinatorial effect of radiation and gossypol would induce higher level of cell death on human glioma cell line U-87 MG than single agent treatment and its possible mechanism of action. Clonogenic survival assay showed that ionizing radiation plus gossypol significantly inhibited clonogenic growth of irradiated cells as compared with either treatment alone. Acridine orange/etidium bromide staining confirmed that there was no significant increase in necrotic and apoptotic cells, but irradiated cells in combination with gossypol showed a significant increase in accumulation of acidic vesicular organelle. The results obtained herein indicated that gossypol is a promising drug that induced autophagic cell death in radioresistant malignant glioma.
\end{abstract}

Key words: Gossypol — Radiation — Autophagy — Malignant glioma

\section{Introduction}

Glioblastomas are the most common and the most aggressive kind of primary brain tumors. Despite recent attempts to improve current therapies and develop new clinical approaches, the median survival of patient with glioma is only 9-12 months (Scott et al. 1998). Malignant glioma is usually treated with surgery, chemotherapy, and radiation therapy. Radiation therapy is a very effective method that can be used alone or in combination with adjuvant therapy. Although apoptosis has mainly been studied over the past decade, it is not a major form of radiation induced cell death (Verheij and Bartelink 2000).

Correspondence to: Bahram Goliaei, Laboratory of Biophysics and Molecular Biology, Institute of Biochemistry and Biophysics (IBB), University of Tehran, P.O. Box 13145-1384, Tehran, Iran

E-mail: goliaei@ibb.ut.ac.ir Hodakeshmiri@ibb.ut.ac.ir
Recently, many modes of radiation cell death, such as autophagy, necrosis, mitotic catastrophe, and senescence have been reported (Riccia and Zong 2006; Eriksson and Stigbrand 2010; Kondo 2013). Apoptosis (type I programmed cell death) is the cell suicide process that defective and useless cells are removed during natural growth and development (Wyllie 2010). Apoptosis is defined by morphological features including chromatin condensation, nuclear fragmentation, DNA laddering, membrane blebbing, and formation of apoptotic bodies (Potten et al. 2001; Fulda and Debatin 2006). Autophagy (type II programmed cell death) is so-called 'self-eating' responsible for long-lived protein degradation and intracellular components turnover. During autophagy, cytosolic components are separated from the rest of cell within the autophagosomes, which are then joined with lysosomes and degraded or recycled. Several stimuli, such as ionizing radiation, endoplasmic-reticulum (ER) stress, and chemotherapeutic drugs can induce apoptosis or autophagy (He and Klionsky 2009; Chen and White 2011). 
In contrast, necrosis is the pathological process and uncontrolled cell death can be caused by serious physical or chemical insult. Morphologic characteristics of necrosis include cellular energy depletion, loss of membrane integrity, and loss of function of homeostatic ion pumps/channels (Cookson and Fink 2005; Kanduc et al. 2002).

Overexpression of antiapoptotic members of the Bcl-2 family and defects in apoptotic signaling pathways is frequently observed in a variety of human tumors, including gliomas which leads to tumors resistant to apoptosis induced by radiation therapy (Igney and Krammer 2002; Steinbach and Weller 2004; Ziegler 2008) . Recent findings show that antiapoptotic Bcl-2 family members also inhibit autophagy (Shimizu et al. 2004; Maiuri et al. 2007; Oberstein et al. 2007). Therefore, prevention of the antiapoptotic activities of Bcl-2 family members is capable of inducing both apoptotic and autophagic cell death.

Gossypol, a natural polyphenolic compound from cottonseed has been recognized as inhibitor of antiapoptotic Bcl-2 family proteins and induces apoptosis in tumor cell lines (Kitada et al. 2003; Zhang et al. 2003; Xu et al. 2005; Zerp et al. 2009; Moretti et al. 2010).

Thus, gossypol by binding to the $\mathrm{BH} 3$ domain of $\mathrm{Bcl}-2$ family member also is capable of activating autophagy. It has been found to be well tolerated and several evidences indicate that this novel compound can be useful for therapy resistance of malignant gliomas (Voss et al. 2010).

In this research we describe the cell death induced by ionizing radiation and gossypol in the human glioma cell line U-87 MG. We test whether the combination of both treatments would induce higher level of cell death than single agent treatment and characterized the types of cell death.

\section{Materials and Methods}

\section{Cell line and reagents}

Human glioblastoma cell line U-87 MG was obtained from the Pasteur Institute of Iran. Gossypol (Tocris) was dissolved in DMSO (Merck, Germany) before usage. Acridine orange and ethidium bromide dyes were purchased from Hopkins \& Williams Ltd. (Chadwell Health, England) and Merck (Germany), respectively.

\section{Cell culture}

Cells were maintained at $37^{\circ} \mathrm{C}$ in $5 \% \mathrm{CO}_{2}$ and $95 \%$ air under sterile conditions in RPMI-1640 culture medium (Gibco, UK), supplemented with $10 \%$ fetal bovine serum plus 200 $\mu \mathrm{g} / \mathrm{ml}$ streptomycin (Jaberebn-Hayan,Tehran, Iran) and 500 units/ml penicillin (Sigma, USA). Subsequently, cells were subcultured 2 to 3 times weekly to maintain in exponential growth phase.

\section{Growth curve and doubling time assay}

Cells were cultured at a density of 10000 cells/well in 24well plates. Plates were incubated at $37^{\circ} \mathrm{C}$ in the humidified atmosphere of $5 \% \mathrm{CO}_{2}$ for 10 days. Every 24 hours, cells from triplicate wells were removed randomly by $0.25 \%$ trypsin and $0.03 \%$ ethylenediaminetetraacetic acid (EDTA) (Sigma) in phosphate buffer saline (PBS) then counted in a hemocytometer. Results were plotted in a log-linear mode and the population doubling time was determined according to the gradiant of the linear region (exponential phase) of the growth curve.

\section{Trypan blue exclusion assay}

The cytotoxic effect of gossypol on malignant glioma cells was determined by using trypan blue exclusion test. Briefly, cells $\left(5 \times 10^{3}\right.$ cells/well) were seeded in 96 -well plates in quintuplicate then incubated overnight at $37^{\circ} \mathrm{C}$. After exposure to various concentrations of the gossypol $(10,25,50,100$, or $150 \mu \mathrm{M}$ ) or vehicle (DMSO) for $48 \mathrm{~h}$, cells were detached by trypsinization and were mixed with trypan blue at a ratio of 9:1. Finally viable cells (unstained) were counted with a hemocytometer. Gosssypol was added to $200 \mu \mathrm{l}$ medium containing $0.1 \%$ DMSO.

\section{Clonogenic survival assays}

Cells were seeded into T-25 flask at a density of 10000 cells/ $\mathrm{cm}^{2}$. After $24 \mathrm{~h}$, cultures were irradiated at doses of $0,2,4$, and $6 \mathrm{~Gy}$ alone or in combination with gossypol administered $24 \mathrm{~h}$ following irradiation (post-irradiation gossypol). Cells were irradiated at room temperature with 6 MV X-ray photons on a Siemens Primus (Germany) linear accelerator at a rate of $2 \mathrm{~Gy} / \mathrm{min}$. Colony formations after 9 days incubation was assessed by crystal violet staining and the colonies with over 50 cells were counted. The surviving fraction was defined as the ratio between the number of colonies in irradiated culture and in unirradiated sample, and it was calculated at each dose level.

\section{Apoptosis and necrosis assay}

Morphological changes due to apoptosis and necrosis induced by radiation alone and the combination treatment with gossypol were examined with acridine orange/ethidium bromide $(\mathrm{AO} / \mathrm{EtBr})$ staining. For this purpose, the cells were collected and washed with cold PBS and then adjusted to a cell density of $1 \times 10^{6}$ cells $/ \mathrm{ml}$ using PBS. The $\mathrm{AO} / \mathrm{EtBr}$ solution $(1: 1, \mathrm{v} / \mathrm{v})$ was added to the cell suspen- 
sion in a final concentration of $100 \mu \mathrm{g} / \mathrm{ml}$. The cellular morphology was viewed by Axoscope 2 under fluorescence microscope (ZEISS, Yena, Germany). Viable, apoptotic and necrotic cells in at least 200 cells were counted to calculate the fraction of apoptotic and necrotic cells (Kasibhatla et al. 2006).

Acridine orange staining assay for autophagy using flow cytometry

The volume of the cellular acidic compartment is increased in autophagy. Thus, it is possible to scan the development of acidic vesicular organelles during autophagy with acidotropic dye acridine orange staining. The intensity of the red fluorescence is proportional to the degree of acidity (Ito et al. 2006; Iwamaru et al. 2007; Jiang et al. 2007). U-87 MG cells were plated in T-25 flask then irradiated with or without gossypol. After $48 \mathrm{~h}$ incubation cells were stained with $1 \mu \mathrm{g} / \mathrm{ml}$ acridine orange for $15 \mathrm{~min}$. consequently removed the medium and separated the cells with trypsin-EDTA, and suspend in phenol red-free growth medium. Green (510-530 nm, FL1-H channel) and red (>650 nm, FL3-H channel) fluorescence emission from $10^{4}$ cells illuminated with blue $(488 \mathrm{~nm})$ excitation light was measured with a Cy Flow Space (Parpec, Germany) using FloMax software (Jiang et al. 2009).

\section{Statistical analysis}

All the experiments were repeated at least three times. The statistical difference between the treatment groups and the untreated control was analyzed by using Student's $t$-test (two-tailed). Values of $p<0.05$ were considered significant.

\section{Results}

\section{Growth kinetics of U-87 MG cells}

Population doubling time refers to the time required for growth of cell to double. So it can be an important parameter in estimating time required for forming a colony. Growth curve also show cell proliferation rate and tumorigenicity of glioma cells. The doubling time of U-87 MG cells was approximately 28.56 hours (Fig. 1).

\section{Effect of gossypol on cell viability of U-87 MG cells}

To evaluate the antitumor effect of gossypol on malignant glioma, we treated cells with $0-150 \mu \mathrm{M}$ of gossypol for $48 \mathrm{~h}$ and their growth patterns were established by trypan blue exclusion test. As shown in Fig. 2, treatment with

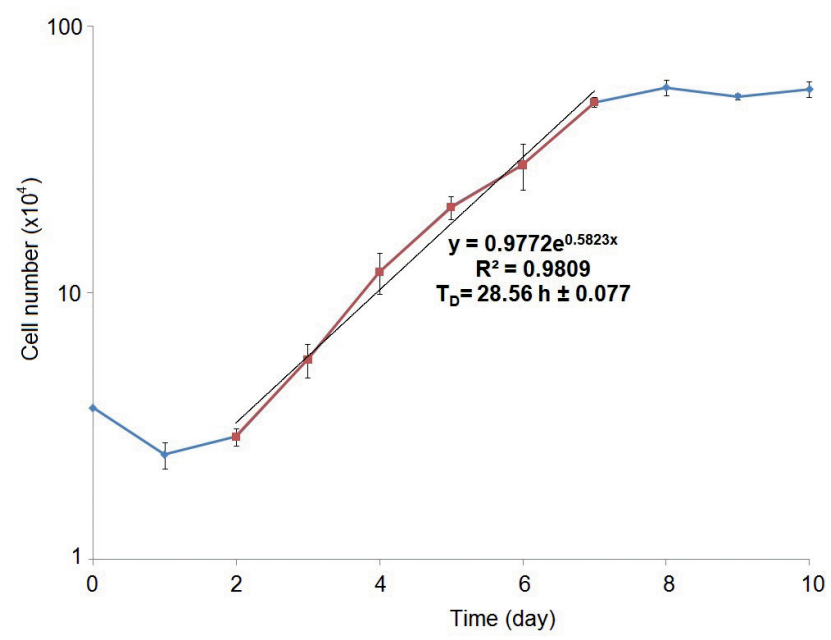

Figure 1. The growth kinetic curve of U-87 MG cell line. Each time point represented the average value of 9 counts. Mean \pm SEM of three experiments. The population doubling time $\left(\mathrm{T}_{\mathrm{D}}\right)$ were calculated from the linear region (exponential phase) of the curve.

gossypol inhibited the proliferation of U-87 MG cells in a dose-dependent manner. Our results showed that more than $90 \%$ of cells were viable after $48 \mathrm{~h}$ of incubation at concentrations lower than $10 \mu \mathrm{M}$. The $\mathrm{IC}_{50}$ value (concentration resulting in cell viability of $50 \%$ of control) was calculated $57 \mu \mathrm{M}$.

Morphological changes of cells were observed via inverted microscope. Control and DMSO samples had regular size, with an elongated shape and large cytoplasm. In the presence of gossypol, cells appeared spherical and gradually detached from substrate. Additionally, granularity and cytoplasmic vacuolation appeared in cells (Fig. 3).

\section{Effect of gossypol on colonogenic survival of U-87 MG cells}

To examine the effect of gossypol on colony formation, cells were exposed to increasing concentrations of gossypol $(0-150 \mu \mathrm{M})$ or vehicle (DMSO) for $48 \mathrm{~h}$ and were seeded in $60 \mathrm{~mm}$ petri dishes at various cell densities. After 9 days, the resulting colonies were fixed with formaldehyde, stained with crystal violent and counted. Plating efficiency was calculated as number of colonies formed/number of cells plated $\times 100$. Gossypol inhibited colony formation in a dose-dependent manner (data not shown).

According to Fig. 4, treatment of U-87 MG cells with $1 \mu \mathrm{M}$ of gossypol did not have any significant effect on plating efficiency $(p>0.05)$, since treatment with 5 and $10 \mu \mathrm{M}$ significantly reduced the plating efficiency $(p<0.01)$. Therefore, $1 \mu \mathrm{M}$ that had no significant effect on cell viability and plating efficiency was taken as non-toxic dosage for further studies ( $p>0.05$ ). 


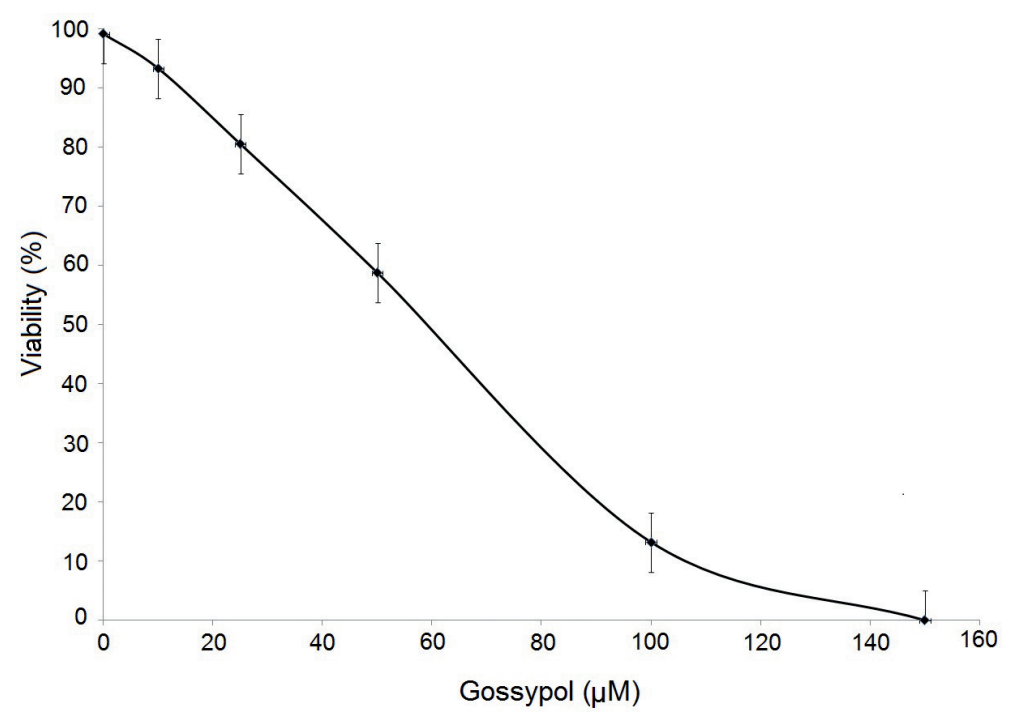

Figure 2. Dose-dependent effect of gossypol on cell viability in U-87 MG cell line. Cells were exposed to different concentrations of gossypol for $48 \mathrm{~h}$ and then viable cells were evaluated by trypan blue exclusion. The $\mathrm{IC}_{50}$ for gossypol was calculated as $57 \mu \mathrm{M}$. Each value represents the mean \pm SD of three independent experiments.
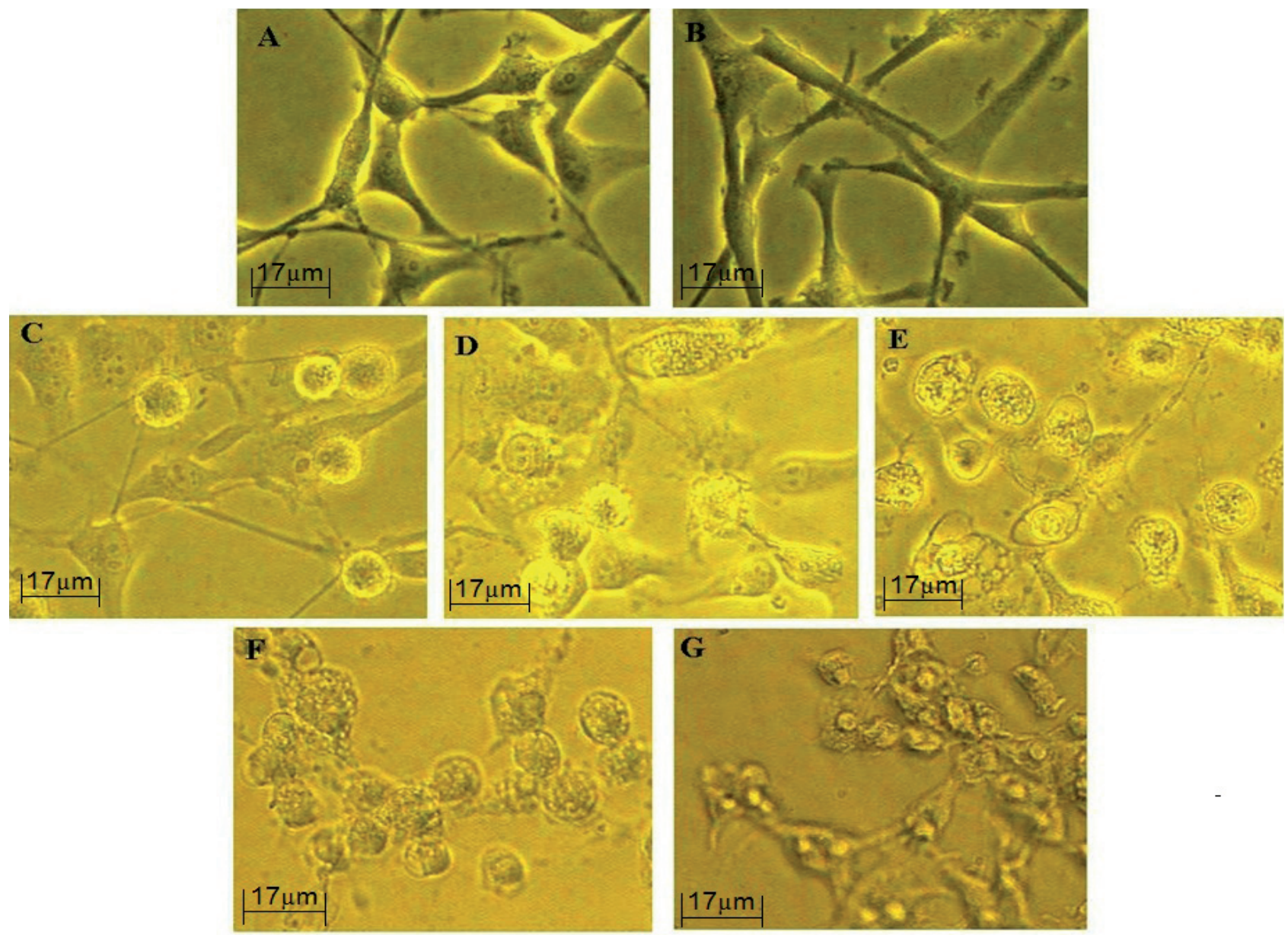

Figure 3. Effect of gossypol on morphological changes of the U-87 MG cells. Cells were exposed to different concentrations of gossypol for $48 \mathrm{~h}$, and images were taken with a Zeiss 405M inverted microscope. Samples as follows: control (A), DMSO (B), $10 \mu \mathrm{M}(\mathbf{C}), 25 \mu \mathrm{M}$ (D), $50 \mu \mathrm{M}(\mathbf{E}), 100 \mu \mathrm{M}(\mathbf{F})$ and $150 \mu \mathrm{M}$ (G) gossypol. 
Effects of gossypol on the radiation response of $U-87 M G$ cells in clonogenic assay

To investigate whether gossypol modulated the response of malignant glioma cells to radiation, cultures were irradiated with increasing doses of $\mathrm{X}$ - rays (0-6 Gy) and then treated with non-toxic dose of gossypol $(1 \mu \mathrm{M})$. Fig. 5 shows that treatment of U-87 MG cells with gossypol plus radiation significantly reduced surviving fractions compared with radiation alone $(p<0.05)$. According to this test measured survival values were less than those are expected. (Data not shown). Therefore this test revealed a clear synergistic interaction between radiation and gossypol.

Linear-quadratic analysis of the radiation survival curve demonstrated following radiation plus gossypol treatment, a value (represents curve's initial slope) increased from 0.052 in radiation alone to 0.229 in combined treatment. Fitted parameters for Linear-quadratic model are shown in Table 1.

\section{Quantification of cell death induced by radiation and gossypol} treatment

To understand the underlying mechanism of radiation-induced cytotoxicity in U-87 MG cells, we quantified the extent of apoptosis, necrosis, and autophagy. $\mathrm{AO} / \mathrm{EtB}$ staining was

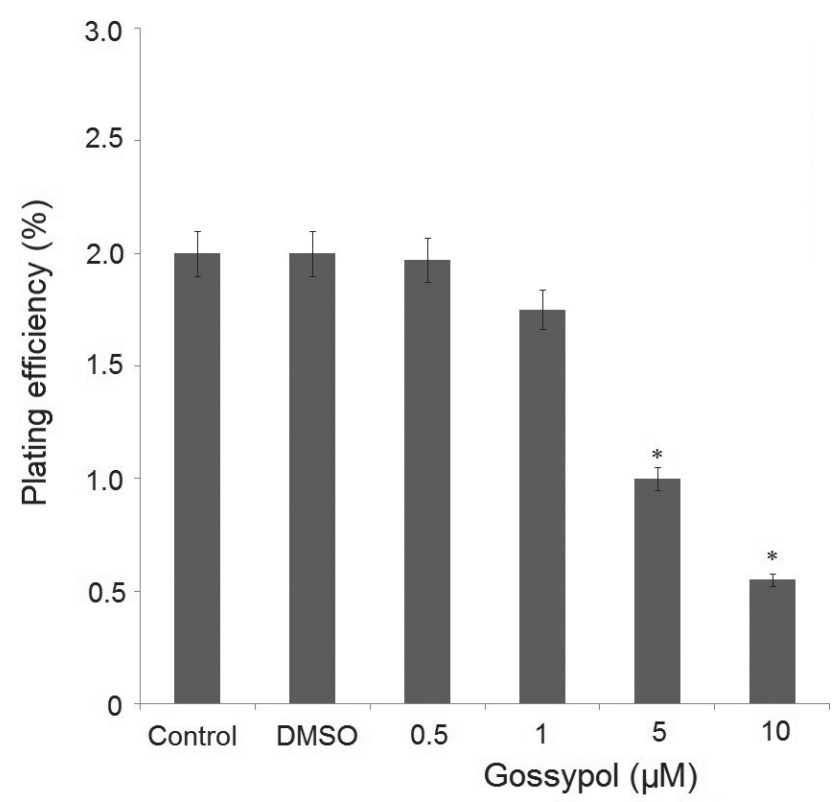

Figure 4. The inhibitory effect of gossypol on plating efficiency in U-87 MG cells. Influence of different concentrations of gossypol on the number of colony forming cells, as evaluated by clonogenic assay. The results are reported from three independent experiments in triplicate. ${ }^{*} p<0.01 v s$. control group.
Table 1. Values of $\alpha$ and $\beta$ parameters calculated by fitting the linear quadratic model to clonogenic survival curve

\begin{tabular}{lcc}
\hline Treatment & $\alpha$ value & $\beta$ value \\
\hline Radiation & 0.052 & 0.042 \\
Radiation+Gossypol & 0.229 & 0.031 \\
\hline
\end{tabular}

performed to detect apoptosis and necrosis and flow cytometric analysis was used to detect autophagy.

Fig. 6 displays nuclear changes of apoptotic and necrotic cells treated with radiation alone or gossypol plus radiation. Fig. 7 compared the percentage of apoptosis, necrosis, and autophagy. Based on these result, the maximum observed apoptosis and necrosis were $7 \%$ and $4 \%$, respectively. The findings showed no major apoptotic and necrotic cell fraction after treatment with radiation and the combination of two agents, additionally enhanced necrosis is not significant $(p>0.05)$.

In contrast, Fig. 8 indicates that radiation alone and combination treatment with gossypol show a significant increase in accumulation of acidic vesicular organelles (the dots above the bar). Raw data from single representative experiment are presented in panel.

Our findings indicated that $27 \%, 33 \%$, and $37 \%$ of U-87 MG cells underwent autophagy following $48 \mathrm{~h}$ exposure to 2,4 , and 6 Gy radiations with gossypol $(p<0.01)$.

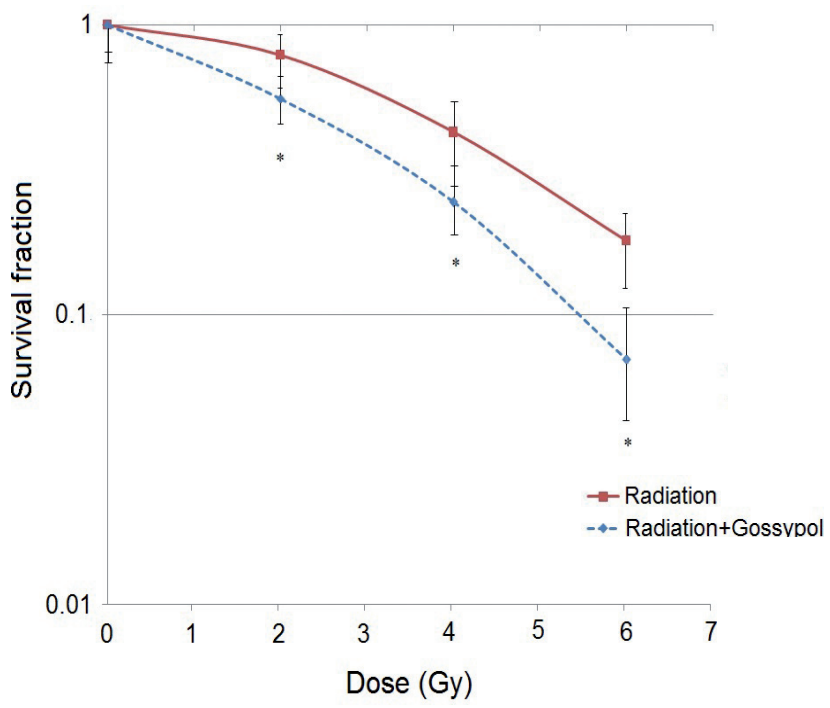

Figure 5. Survival curve of U-87 MG cells following X-ray irradiation, with or without gossypol treatment. Control cells and cells treated with gossypol $(1 \mu \mathrm{M})$ were irradiated with X-ray at $6 \mathrm{MV}$ energy and $2 \mathrm{~Gy} / \mathrm{min}$ dose rate at room temperature with doses up to $6 \mathrm{~Gy}$. The survival curves were plotted with linear-quadratic model. Data points and bars represent the average and standard error of 3 separate experiments. ${ }^{\star} p<0.05 v$ s. radiation group. 

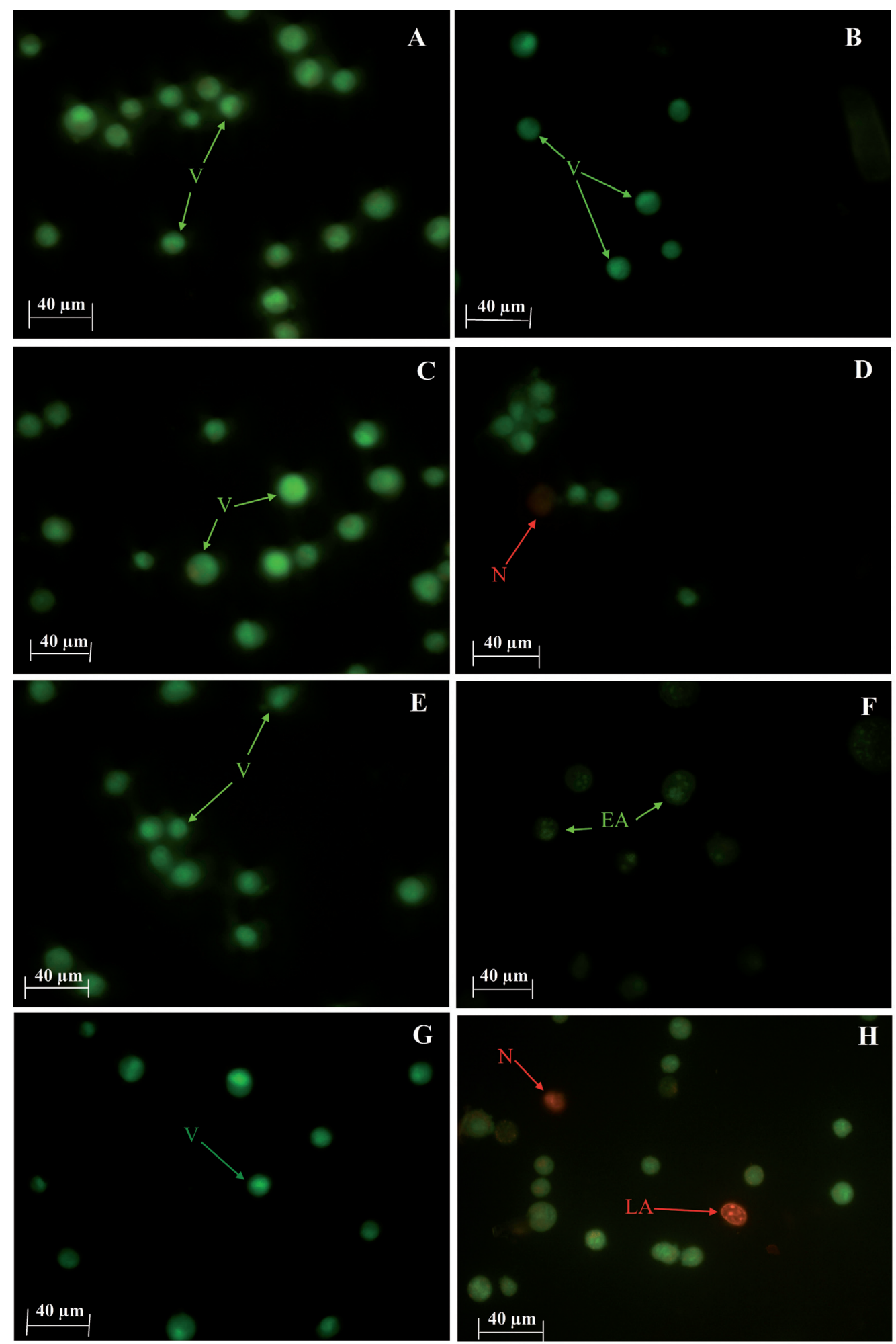

Figure 6. Morphological assessment of apoptosis and necrosis in U-87 MG cells. AO/EtBr double staining of U-87 MG cells shows live cells are uniformly green ( $\mathrm{V}$, arrows), early apoptotic cells are green with bright green dots in their nuclei (EA, arrows) as a consequence of chromatin condensation and nuclear fragmentation. Late apoptotic cells (LA, arrow) are orange and in contrast to necrotic cells (N, arrows) they show condense fragmented nuclei. Control (A), 2 Gy (B), 4 Gy (C), 6 Gy (D), Gossypol (E), 2 Gy+Gossypol (F), 4 Gy+Gossypol (G), 6 Gy+Gossypol (H). 
These results indicate that glioblastoma cells seem to be less resistant to therapies that induce autophagy.

\section{Discussion}

Radiation therapy is widely used for cancer treatment. The expansion of resistance and recurrence of cancer are the primary limitations of radiation therapy. In order to overcome these limitations, combination therapy can be a beneficial and effective approach. In this study, we used the natural pan-Bcl-2 inhibitor gossypol which is orally applicable and well tolerated, without particular toxicities in patients with recurrent glioblastoma. In order to evaluate the effect of radiation with gossypol on cell death of malignant glioma, we selected a typical glioma cell line U-87 MG.

In this research, gossypol successfully showed dosedependent inhibition of cellular proliferation and colony formation ability of malignant glioma cell line. These results indicate that gossypol is able to induce both interphasic and reproductive death in U-87 MG cells. For evaluation of radiosensitivity, we selected non-toxic dose $(1 \mu \mathrm{M})$ of gossypol to ensure that the growth inhibitory effect of gossypol plus radiation on glioma cells was not a consequence of cytotoxicity of gossypol.

Clonogenic survival assay demonstrated that gossypol significantly inhibits clonogenic growth of irradiated cells when compared with radiation treatment alone. Thus it can be concluded that gossypol significantly reduces the radiation resistance of $\mathrm{U}-87 \mathrm{MG}$ cell line. Fitted parameters using Linear-quadratic model indicated a 4.5 -fold increase in $\alpha$ value and minimal decrease in $\beta$ value in the survival response curve. In radiobiological terms, increase in a value means an increase of irreversible damages while decrease in $\beta$ indicates a reduction of repairable damages (Kellerer and Rossi 1972; Chadwick and Leenhouts 1973). Based on this model, we found out that following gossypol plus radiation treatment increase irreversible damages such as DNA double-strand breaks while reversible damages such as DNA single-strand breaks decrease.

In order to reveal the molecular mechanism behind the higher toxicity of the combination treatment in U-87 MG cell line, we compared the effects of radiation treatment individually with combinatorial effect of radiation and gossypol, on induction of different types of cell death like apoptosis, necrosis, and autophagy.

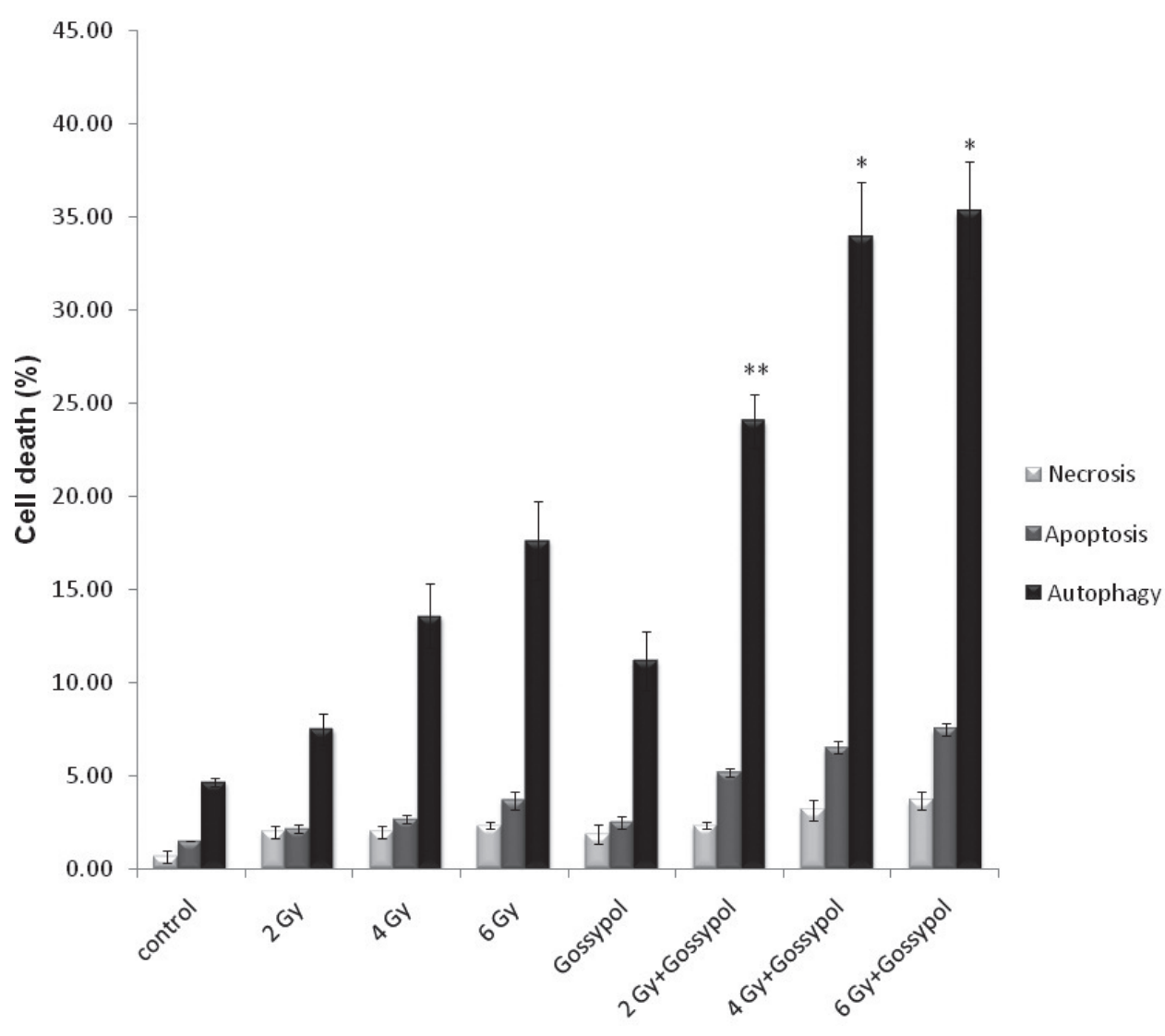

Figure 7. Comparison of the three types of cell death induced by radiation treatment individually and combinatorial effect of radiation and gossypol. Cells were treated with $1 \mu \mathrm{M}$ gossypol for 48 hours following irradiation (0-6 Gy), next stained with acridine orange/ ethidium bromide double staining and then the percentage of apoptotic and necrotic cells were measured. The ratio of the cells with autophagic vacuoles was quantified by flow cytometry. The numbers indicate the percentage of cells with acidic vesicular organelles. Results are presented as mean \pm SEM of 3 independent experiments. Compared to radiation group; ${ }^{*} p<0.01$ and ${ }^{* *} p<0.001$. 


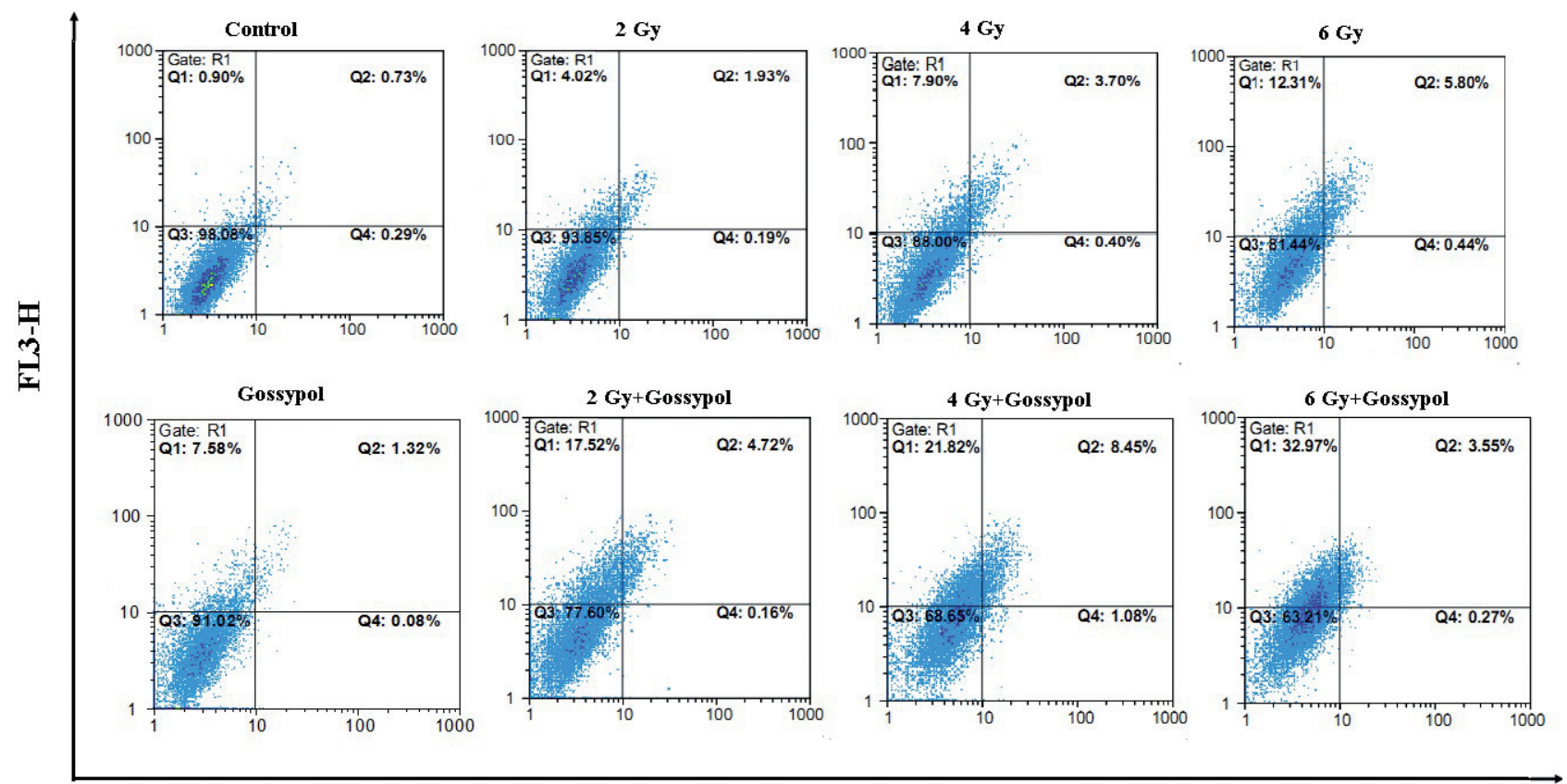

FL1-H

Figure 8. Influence of radiation and combination treatment with gossypol on autophagy induction in the U-87 MG cell line. Irradiated cells were incubated with $1 \mu \mathrm{M}$ gossypol. After $48 \mathrm{~h}$ incubation, cells were stained with acridine orange and the intensity of the red and green fluorescence was monitored by flow cytometry in FL1-H and FL3-H channel, respectively. Raw data from single representative experiment are presented in dot plot panel.

In present study, U-87 MG cells showed minimum apoptosis, as previously shown by Voss et al. (2010). High resistance against apoptosis is a major feature of malignant gliomas. Activation of the proapoptotic Bcl-2 family members Bax and Bak is a crucial stage that triggers mitochondrial (intrinsic) pathway of apoptosis. The intrinsic pathway is inhibited by antiapoptotic Bcl-2 family members (such as $\mathrm{Bcl}-2, \mathrm{Bcl}-\mathrm{xL}$, and Mcl-1) known to be highly overexpressed in malignant gliomas. In addition to defects in apoptotic signaling pathways, they play fundamental role in radioresistance of malignant gliomas.

On the other hand, since necrosis is induced by especially strong stimuli, like high radiation doses, it is not surprising that we observe no significant necrosis. Our data are consistent with Akagi et al. (1993), in which treatment Molt-4 cells with various radiation doses potentiated typical necrosis at doses higher than $100 \mathrm{~Gy}$.

Our study demonstrated that prevailing mechanism of U-87 MG cell death in response to radiation, gossypol, and combination of two agents was not as a result of apoptosis or necrosis, but based on the flow cytometry analysis results (Fig. 7), autophagy is a predominant form of glioma cell death. Autophagy is an intracellular degradation process that transfers cytosolic components to the lysosome for deposition. This process is regulated by Atg genes. Beclin 1, the mammalian orthologue of yeast Atg6, has an important role in autophagy (Kang et al. 2011). Recent researches showed that antiapoptotic Bcl-2 family members also can bind to Atg6/Beclin 1 and inhibit autophagy (Kitada et al. 2003; Shimizu et al. 2004; Maiuri et al. 2007; Oberstein et al. 2007). In apoptosis-resistant malignant glioma cells, gossypol binds to antiapoptotic Bcl-2 family members and releases Beclin 1 at the endoplasmic-reticulum, so it preferentially induces autophagic cell death.

There are also evidences that show the prosurvival Bcl-2 family members have an antioxidant activity and play an important preventive role in developing reactive oxygen species. In addition, they increase antioxidant enzyme activities like glutathione and also moderate the cellular redox homeostasis. Therefore, inhibition of prosurvival members of Bcl-2 family by gossypol can interfere with antioxidant capacity of tumor cells and finally stimulates autophagy induced by radiation in tumor cells (Jang and Surh 2003). However, further investigation on the exact mechanisms is needed for therapeutic exploitation of gossypol in radiotherapy clinical science.

In conclusion, our data indicate that the naturally occurring $\mathrm{BH} 3$ mimetic gossypol decreases radioresistance of glioblastoma multiform cell line. Furthermore, gossypol significantly enhances the antitumor activity of ionizing radiation by increasing induction of autophagy. These re- 
sults also provide evidences for using gossypol to improve the outcome of current malignant glioma radiotherapy and represent new promising mechanism that may lead to new glioma therapies.

Acknowledgement. This work was supported by grant from INSF and educational grant from University of Tehran.

\section{References}

Akagi Y., Ito K., Sawada S. (1993): Radiation-induced apoptosis and necrosis in Molt-4 cells: a study of dose-effect relationships and their modification. Int. J. Radiat. Biol. 64, 47-56 http://dx.doi.org/10.1080/09553009314551101

Chadwick K. H., Leenhouts H. P. (1973): A molecular theory of cell survival. Phys. Med. Biol. 18, 78-87 http://dx.doi.org/10.1088/0031-9155/18/1/007

Chen H. Y., White E. (2011): Role of autophagy in cancer prevention. Cancer Prev. Res. 4, 973-983 http://dx.doi.org/10.1158/1940-6207.CAPR-10-0387

Cookson B., Fink S. (2005): Apoptosis, Pyrptosis and Necrosis: Mechanistic description of dead and dying cell in eukaryotic cells. Infect Immun. 73, 1907-1916 http://dx.doi.org/10.1128/IAI.73.4.1907-1916.2005

Eriksson D., Stigbrand T. (2010): Radiation-induced cell death mechanisms. Tumor Biol. 31, 363-372 http://dx.doi.org/10.1007/s13277-010-0042-8

Fulda S., Debatin K. (2006): Extrinsic versus intrinsic apoptosis pathways in anticancer chemotherapy. Oncogene 25, 4798-4811 http://dx.doi.org/10.1038/sj.onc.1209608

He C., Klionsky D. J. (2009): Regulation mechanisms and signaling pathways of autophagy. Annu Rev. Genet. 43, 67-93 http://dx.doi.org/10.1146/annurev-genet-102808-114910

Igney F. H., Krammer P. H. (2002): Death and anti-death: tumor resistance to apoptosis. Nat. Rev. Cancer. 2, 277-288 http://dx.doi.org/10.1038/nrc776

Ito H., Aoki H., Kühnel F., Kondo Y., Kubicka S., Wirth T., Iwado E., Iwamaru A., Fujiwara K., Hess K. R., Lang F. F., Sawaya R., Kondo S. (2006): Autophagic cell death of malignant glioma cells induced by a conditionally replicating adenovirus. J. Natl. Cancer Inst. 98, 625-636 http://dx.doi.org/10.1093/jnci/djj161

Iwamaru A., Kondo Y., Iwado E., Aoki H., Fujiwara K., Yokoyama T., Mills G. B., Kondo S. (2007): Silencing mammalian target of rapamycin signaling by small interfering RNA enhances rapamycin-induced autophagy in malignant glioma cells. Oncogene 26, 1840-1851 http://dx.doi.org/10.1038/sj.onc.1209992

Jang J. H., Surh Y. J. (2003): Potentiation of cellular antioxidant capacity by Bcl-2: implications for its antiapoptotic function. Biochem. Pharmacol. 66, 1371-1379 http://dx.doi.org/10.1016/S0006-2952(03)00487-8

Jiang H., White E. J., Conrad C., Gomez-Manzano C., Fueyo J. (2009): Autophagy pathways in glioblastoma. Meth. Enzymol. 453, 273-286 http://dx.doi.org/10.1016/S0076-6879(08)04013-5
Jiang H., Gomez-Manzano C., Aoki H., Alonso M. M., Kondo S., McCormick F., Xu J., Kondo Y., Bekele B. N., Colman H., Lang F. F., Fueyo J. (2007): Examination of the therapeutic potential of Delta-24-RGD in brain tumor stem cells: Role of autophagic cell death. J. Natl. Cancer Inst. 99, 1410-1414 http://dx.doi.org/10.1093/jnci/djm102

Kanduc D., Mittelman A., Serpico R., Sinigaglia E., Sinha A. A., Natale C., Santacroce R., Di Corcia M.G., Lucchese A., Dini L., Pani P., Santacroce S., Simone S., Bucci R., Farber E. (2002): Cell death: apoptosis versus necrosis (review). Int. J. Oncol. 21, 165-170

Kang R., Zeh H. J., Lotze M. T., Tang D. (2011): The Beclin 1 network regulates autophagy and apoptosis. Cell Death Differ. $18,571-580$ http://dx.doi.org/10.1038/cdd.2010.191

Kasibhatla S., Amarante-Mendes G. P., Finucane D., Brunner T., Bossy-Wetzel E., Green D. R. (2006): Acridine Orange/Ethidium Bromide (AO/EB) Staining to Detect Apoptosis. Cold Spring Harb. Protoc.

Kellerer A. M, Rossi H. H. (1972): The theory of dual of radiation action. Curr. Top. Radiat. Res. 75, 471-488 http://dx.doi.org/10.2307/3574835

Kitada S., Leone M., Sareth S., Zhai D., Reed J. C., Pellecchia M. (2003): Discovery, characterization, and structure-activity relationships studies of proapoptotic polyphenols targeting B-cell lymphocyte/leukemia-2 proteins. J. Med. Chem. 46, 4259-4264 http://dx.doi.org/10.1021/jm030190z

Kondo T. (2013): Radiation-induced cell death and its mechanisms. Rad. Emerg. Med. 2, 1-3

Maiuri M. C., Le Toumelin G., Criollo A., Rain J. C., Gautier F., Juin P., Tasdemir E., Pierron G., Troulinaki K., Tavernarakis N., Hickman J. A., Geneste O., Kroemer G. (2007): Functional and physical interaction between $\mathrm{Bcl}-\mathrm{X}(\mathrm{L})$ and a BH3-like domain in Beclin-1. EMBO J. 26, 2527-2539 http://dx.doi.org/10.1038/sj.emboj.7601689

Moretti L., Li B., Kim K. W., Chen H., Lu B. (2010): AT-101, a Pan-Bcl-2 inhibitor, leads to radiosensitization of nonsmall cell lung cancer. J. Thorac. Oncol. 5, 680-687

Oberstein A., Jeffrey P. D., Shi Y. (2007): Crystal structure of the Bcl-XL-Beclin1 peptide complex: Beclin 1 is a novel BH3-only protein. J. Biol. Chem. 282, 13123-13132 http://dx.doi.org/10.1074/jbc.M700492200

Potten C., Booth C., Renehan A. (2001): What is apoptosis and why it is important. BMJ 322, 1536-1538 http://dx.doi.org/10.1136/bmj.322.7301.1536

Riccia M. S., Zong W. X. (2006): Chemotherapeutic approaches for targeting cell death pathways. Oncologist 11, 342-357 http://dx.doi.org/10.1634/theoncologist.11-4-342

Scott C. B., Scarantino C., Urtasun R., Movsas B., Jones C. U., Simpson J.R., Fischbach A. J., Curran WJ. Jr. (1998): Validation and predictive power of Radiation Therapy Oncology Group (RTOG) recursive partitioning analysis classes for malignant glioma patients: a report using RTOG 90-06. Int. J. Radiat. Oncol. Biol. Phys. 40, 51-55 http://dx.doi.org/10.1016/S0360-3016(97)00485-9

Shimizu S., Kanaseki T., Mizushima N., Mizuta T., Arakawa-Kobayashi S., Thompson C. B., Tsujimoto Y. (2004): Role of Bcl-2 
family proteins in a non-apoptotic programmed cell death dependent on autophagy genes. Nat. Cell Biol. 6, 1221-1228 http://dx.doi.org/10.1038/ncb1192

Steinbach J. P., Weller M. (2004): Apoptosis in gliomas: molecular mechanisms and therapeutic implications. J. Neurooncol. 70, 247-256 http://dx.doi.org/10.1007/s11060-004-2753-4

Verheij M., Bartelink H. (2000): Radiation-induced apoptosis. Cell Tissue Res. 301, 133-142 http://dx.doi.org/10.1007/s004410000188

Voss V., Senft C., Lang V., Ronellenfitsch M. W., Steinbach J. P., Seifert V., Kögel D. (2010): The pan-Bcl-2 inhibitor (-)-Gossypol triggers autophagic cell death in malignant glioma. Mol. Cancer Res. 8, 1002-1016 http://dx.doi.org/10.1158/1541-7786.MCR-09-0562

Wyllie A. H. (2010): Roche Applied Science: Apoptosis, Cell Death, and Cell Proliferation Manual: 3rd edition, p. 59

Xu L., Yang D., Wang Sh., Tang W., Liu M., Davis M., Chen J., Rae J. M., Lawrence T., Lippman M. E. (2005): (-)-Gossypol enhances response to radiation therapy and results in tumor regression of human prostate cancer. Mol. Cancer Ther. 4, 197-205

Zerp S. F., Stoter R., Kuipers G., Yang D., Lippman M. E., Blitterswijk W. Jv., Bartelink H., Rooswinkel R., Lafleur V., Verheij M. (2009): AT-101, a small molecule inhibitor of anti-apoptotic Bcl-2 family members, activates the SAPK/JNK pathway and enhances radiation-induced apoptosis. Radiat. Oncol. 4, 47 http://dx.doi.org/10.1186/1748-717X-4-47

Zhang M., Liu H., Guo R., Ling Y., Wu X., Li B., Roller P. P., Wang S., Yang D. (2003): Molecular mechanism of gossypol-induced cell growth inhibition and cell death of HT-29 human colon carcinoma cells. Biochem. Pharmacol. 66, 93-103 http://dx.doi.org/10.1016/S0006-2952(03)00248-X

Ziegler D.S., Kung A. L., Kieran M. W. (2008): Anti-apoptosis mechanisms in malignant gliomas. J. Clin. Oncol. 26, 493-500 http://dx.doi.org/10.1200/JCO.2007.13.9717

Received: March 8, 2014

Final version accepted: May 22, 2014

First published online: June 26, 2014 